ORIGINAL ARTICLE

\section{Rooming-in For Babies Born by Caesarean Section in Dr. Cipto Mangunkusumo General Hospital Jakarta}

\author{
RULINA SURADI
}

(From the Dept. of Child Health, Medical School, University of Indonesia)

\section{Abstract}

Rooming-in was started in our hospital in 1981 for newborns born normally. After having good results with this in mid 1984 we started rooming-in for babies delivered by caesarean section if they fulfilled a certain criteria. But the facilities for rooming-in for caesaren babies were still limited, so not every baby who fulfilled the criteria could be roomed in with the mother. In the year 1986, 4112 babies were born in our hospital among which 868 were delivered by caesarean section. Of the 868 babies 435 babies fulfilled the criteria but only 269 babies could be roomed in with the mother while 166 babies had to be nursed separately. We compared the data of the rooming-in babies to the babies nursed separately. The study showed that in the rooming-in group more mothers were fully breastfeeding on discharge and incidence of sepsis, enteritis and hyperbilirubinaemia were significantly lower while mortality and the incidence of pneumonia, omfalitis, conjunctivitis and pyodermia did not differ significantly.

\title{
Introduction
}

Rooming-in is a system of caring newborns together with their mothers in one room which enables the mother to be near her baby anytime. Its advantages has been recognized such as early mother-infant bonding, increased prevalence of breastfeeding and reduction of incidence of nosocomial infection. (De Chateau and Wiberg, 1977; Brimblecombe et al., 1979; Djuanda et al., 1979; Suradi, 1983).

Since 1981 we introduced rooming-in for babies delivered normally. After having good results with this in mid 1984 we

\section{Materials and Methods}

This is a retrospective study covering infants delivered by caesarean section in the Dr. Cipto Mangunkusumo General Hospital in the year 1986 who fulfilled the criteria for rooming-in which were :

- Single born

- Apgar Score at 5 minutes, 7 or more

- Birthweight 2000 grams or more

- Gestational age 37 weeks or more

- Without congenital anomalies

- No intrapartal infection

- No fetal distress

- Mother in good condition.

As there was limited space for roomingin for babies delivered by caesarean section not every baby who fulfilled the above mentioned criteria could be cared for together with the mother and had to be nursed separately untill there was space. The babies who were with the mothers for at least the first 48 hours in the rooming-in unit were grouped as roomingin (R.I.) and those who fulfilled the above mentioned criteria but could not be cared for together with the mothers for the introduced this system for babies delivered by caesarean section if mother and baby fulfilled certain criteria. Rooming-in for mothers delivering by caesarean section will give them part of the natural process of giving birth that is breastfeeding. (Frantz and Kalmer, 1979). This study will show us whether rooming-in has its advantages for babies delivered this way by comparing the data of neonates born by caesarean section who were cared together with the mothers to those who fulfilled the criteria of rooming-in but due to lack of facilities had to be nursed separately.

first days of life were grouped as non rooming-in (N.R.I.). Both groups got the same treatment while the mothers were in the recovery room. After rescusitation the baby was put in a room nearby the recovery room. About 4 to 6 hours after delivery when the mother became conscious from the anesthesia the baby was put to his mother's breast to stimulate the milk production. And then every three hours the nurses brought the babies to the mothers untill the mothers and babies were brought to the wards which was about 12 to 24 hours after delivery. The R.I. babies was put in a cot placed near the mother's bed and was helped to nurse on demand from his mother by the nurse untill the mother was able to help herself which is usually on the 3 rd or 4th day. In the first twenty four hours the baby did not get any additional feeding but after 24 hours if breastmilk production was still insufficient that is if the baby was still unsatisfied after breastfeeding we added formula by spoon. The N.R.I. babies were brought to the nursery 
and was formula-fed by bottle untill there was space for rooming in or when the mothers were strong enough to come to the nursery to feed which was at least after the third day.

On discharge we recorded whether the babies were fully breastfeeding, was on mixed feeding or was formula fed. By fully breastfeeding we meant that for at least one day before discharge the baby did not need any addition of formula anymore to be satisfied. By mixed feeding we meant that the main feeding was breastmilk but formula addition was still necesarry for the baby to be satisfied and by formula-fed we meant that the baby's main food is stil formula.

We also recorded the mortality and morbidity of the babies. The diagnosis

of sepsis was based on clinical criteria used in the subdivision of Perinatology Child Health Department of the hospital. Enteritis was diagnosed when the stool became watery with mucus or watery with frequency of at least twice as usual. Pneumonia was diagnosed based on clinical and radiological findings. Omfalitis was diagnosed when the umbilical stump was damp and had a foul smell and the edge was reddish. Conyunctivitis was diagnosed when we found purulent discharge. The diagnosis of pyodermia was based on the findings of pustules on the skin. Hyperbilirubinemia was diagnosed when the total bilirubin in the serum reached $10 \mathrm{mg} \%$ or more.

To grade the significance of difference we used the chi-square test.

\section{Results}

During the year 1986, 4112 deliveries took place in the Dr. Cipto Mangunkusumo General Hospital Jakarta among which 868 were delivered by caesarean section. Of the

435 babies who fulfilled the criteria for rooming-in only 269 could be nursed with the mother and 166 babies had to be nursed separately.

Table 1 : The material for the study

\begin{tabular}{lcc}
\hline & 1986 & $\%$ \\
\hline Total livebirths & 4112 & \\
Total Caesarean & 868 & 21.1 \\
Fulfill criteria & 435 & 50.1 \\
Rooming-in & 259 & 61.8 \\
Non rooming-in & 166 & 39.2 \\
\hline
\end{tabular}

The effect of rooming-in can be seen in the following tables.
Table 2 : Breastmilk pruduction on discharge

\begin{tabular}{|lcccc|}
\hline & $\begin{array}{c}\text { R.I. } \\
(\mathrm{n}=269)\end{array}$ & $\%$ & $\begin{array}{c}\text { N.R.I. } \\
(\mathrm{n}=166)\end{array}$ & $\%$ \\
\hline Fully breastfed & 128 & 47.6 & 8 & 4.8 \\
Mixed feeding & 120 & 44.6 & 114 & 68.7 \\
Formula fed & 21 & 7.8 & 44 & 26.5 \\
\hline
\end{tabular}

Table 3 : Fully breast feeding on discharge

\begin{tabular}{|crcc|}
\hline F.B.F & + & - & N \\
\hline R.I. & 128 & 141 & 269 \\
N.R.I. & 8 & 158 & 166 \\
Total & 136 & 299 & 435 \\
\hline
\end{tabular}

$\mathrm{X}^{2}=85.37 \quad \mathrm{p}<0.01$

Table 4 : The morbidity

\begin{tabular}{|lcccc|}
\hline Morbidity & $\begin{array}{c}\text { R.I. } \\
(\mathrm{n}=269)\end{array}$ & $\%$ & $\begin{array}{c}\text { N.R.I. } \\
(\mathrm{n}=166)\end{array}$ & $\%$ \\
\hline Sepsis & 1 & 0.37 & 15 & 9.04 \\
Enteritis & 4 & 1.48 & 19 & 11.46 \\
Pneumonia & 1 & 0.37 & 4 & 2.40 \\
Omfalitis & 18 & 6.69 & 9 & 5.42 \\
Conjunctivitis & 35 & 13.01 & 11 & 6.62 \\
Pyodermia & 11 & 4.08 & 10 & 6.02 \\
Hyperbilirubinaemia & 51 & 18.95 & 78 & 46.98 \\
\hline
\end{tabular}


Table 5 : Incidence of sepsis

\begin{tabular}{|lccc|}
\hline Sepsis & + & - & N \\
\hline R.I. & 1 & 268 & 269 \\
N.R.I & 15 & 151 & 166 \\
Total & 16 & 419 & 435 \\
\hline
\end{tabular}

$\mathrm{X}^{2}=19.37 \quad \mathrm{p}<0.01$

Table 6 : Incidence of enteritis

\begin{tabular}{|lccc|}
\hline Enteritis & + & - & N \\
\hline R.I. & 4 & 265 & 269 \\
N.R.I. & 19 & 147 & 166 \\
Total & 23 & 412 & 435 \\
\hline
\end{tabular}

$X^{2}=18.39$

$\mathrm{p}<0.01$

Table 7 : The incidence of pneumonia

\begin{tabular}{|lccc|}
\hline Pneumonia & + & - & N \\
\hline R.I. & 1 & 268 & 269 \\
N.R.I. & 4 & 162 & 166 \\
Total & 5 & 430 & 435 \\
\hline
\end{tabular}

$\mathrm{X}^{2}=2.17 \quad \mathrm{p}>0.05$
Table 8 : The incidence of omfalitis

\begin{tabular}{|lrcc|}
\hline Omfalitis & + & - & N \\
\hline R.I. & 18 & 251 & 269 \\
N.R.I. & 9 & 157 & 166 \\
Total & 27 & 408 & 435 \\
\hline
\end{tabular}

$\mathrm{X}^{2}=0.10 \quad \mathrm{p}>0.05$

Table 9 : The incidence of conyunctivitis

\begin{tabular}{|lccc|}
\hline Conyunctivitis & + & - & N \\
\hline R.I. & 35 & 234 & 269 \\
N.R.I. & 11 & 155 & 166 \\
Total & 46 & 389 & 435 \\
\hline
\end{tabular}

$\mathrm{X}^{2}=3.77 \quad \mathrm{p}>0.05$

Table 10 : The incidence of pyodermia

\begin{tabular}{|c|c|c|c|}
\hline Pyodermia & + & - & $\mathbf{N}$ \\
\hline R.I. & 11 & 258 & 269 \\
\hline N.R.I. & 10 & 156 & 166 \\
\hline Total & 21 & 414 & 435 \\
\hline
\end{tabular}


Table 11 : The incidence of hyperbilirubinaemia

\begin{tabular}{|lccc|}
\hline Hyperbilirubinaemia & + & - & N \\
\hline R.I. & 51 & 218 & 269 \\
N.R.I. & 78 & 88 & 166 \\
Total & 129 & 306 & 435 \\
\hline
\end{tabular}

$\mathrm{X}^{2}=37.32 \quad \mathrm{p}<0.01$

Table 12 : The mortality

\begin{tabular}{|lccc|}
\hline Mortality & + & - & N \\
\hline R.I. & 0 & 269 & 269 \\
N.R.I. & 1 & 165 & 166 \\
Total & 1 & 434 & 435 \\
\hline
\end{tabular}

$\mathrm{X}^{2}=0.059 \quad \mathrm{p}>0.05$

\section{Discussion}

Human breastmilk is considered the ideal sinthesis because sucking stimulus decreased. food for infants. For breastfeeding to be successful mother and baby should not be separated during the first 24 hours. (American Academy of Paediatrics, 1978) A baby born by caesarean section is a high risk infant and will need more attention from the nursing staff. The policy in ou hospital before the year 1984 for babies delivered by caesarean section was separation from the mother and nursed in the special care unit. Separation will cause anxiety to the mother which inhibits milk production (Brimblecombe, et al., 1979) and the babies are introduced to the bottle which also results in inhibition of prolactin and milk rooming-in for mothers delivering by caesarean section will give them part of the natural process of giving birth that is breastfeeding. So after having good results with rooming-in for normal deliveries we tried rooming-in for babies delivered by caesarean section if they fulfilled the criteria so that they could get the advantages of roomingin too. For the first criteria we took single born, because twins will bring with it other problems. Apgar score is highly corelated to morbidity and mortality and the Apgar score at 1 minute is still influenced by anesthesia so that we took the Apgar score at 5 minutes for the second criteria. The criteria for birthweight is $\mathbf{2 0 0 0}$ grams or more because from our experience these babies sucking reflexes were strong enough if they were fullterm. The indication for caesarean section should not be due to fetal distress or intrapartal infection, and mother should be well enough to be able to take care of her own baby herself after 3 days.

The results showed that the incidence of mothers fully breastfeeding their babies on discharge were significantly higher in the rooming-in babies than in the separated ones. This is because of the early and frequent sucking of the breast which stimulates the milk production which is made able because of rooming-in. In an earlier survey the authors noted that in rooming-in mothers milk was produced sooner than in mothers whose babies were being separated. (Suradi, 1983) Of the rooming-in group 21 babies were still on formula as the main food. These babies were referred to the special care unit because of morbidity after at least 2 days of roomingin and on discharge mothers milk production was still very scarce.

The incidence of sepsis differs significantly in the rooming-in babies if compared to the separated ones. This is also shown by Monintja et al. (1987) who reported 165 cases of sepsis out of 4112 liveborn newborns in $1986(3.98 \%)$ of which only 5 cases out of $2418(0.16 \%)$ were from the rooming-in unit. The incidence of enteritis was significantly less in the tooming-in unit compared to the non rooming-in unit. This is due to the fact that they got colostrum sooner which we know contains many protecting factors and also because they stayed in an environment familiar to them. This has also been proven by many authors.

The incidence of omfalitis, conjunctivitis and pyodermia seemed higher in the rooming-in babies when compared to the non rooming-in ones but the difference was not significant. This could be because the nurses left the care of the babies too soon to the mothers whose knowledge in hygiene was still limited.

Hyperbilirubinaemia was found more in the non rooming-in group than in the rooming-in unit. This could be because the morbidity was higher in the non roomingin group and the morbidity caused the jaundice.

Death occured only once and that was in the non rooming-in group. Death was due to sepsis.

As conclusion we can say that rooming in has its advantages for babies born by caesarean section if mother and baby fulfilled the above mentioned criteria. 


\section{REFERENCES}

1. American Academy of Pediatrics: Breastfeeding. Pediatrics 62 : $591-598$ (1978).

2. BRIMBLECOMBE, F.S.W.; ROBERTON, N.R.C.; RICHARDS, M.P.M.: Separation and Special Care Baby units. Clinics in developmental medicine, pp 112-118 Spastic International Medial Publ., London, 1978.

3. DE ChateaU, P.; WIBERG, B.: Long term effect on mother infant behaviour of extra contact during the first hour post partum.

1. First observations at 36 hours. Acta paediat. scand. $66: 137-143$ (1977a).

II. A follow-up at three months. Acta paediat. scand. 66 : 145-151 (1977b).
4. DJUANDA, P.; RUSKANDI, M.; ALISYAHBANA, A.: A rooming-in program for mother and newborn in Dr. Hasan Sadikin General Hospital. Paediatr. Indones. 19 : 169-176 (1979).

5. FRANTZ, K.B.; KALMER, B.A.: Breastfeeding works for caesarians too. R.N. 42 : 39-47 (1979).

6. MONINTJA, H.E.; BOEDJANG, R.F.; AMINULLAH, A.; SURADI, R.; KADRI, N.; IRMAN, F.: Experiences with Antibiotics treatment of neonatal sepsis in Dr. Cipto Mangunkusumo General Hospital Jakarta. Presented at the VIIth National Paediatric Congress, Jakarta 1987.

7. SURADI, R.: Rooming-in in the Dr. Cipto Mangunkusumo General Hospital, Proceedings of the First National Conggres of Perinasia: 117-128. Yogyakarta, 1983. 